\title{
Disaster Monitoring of Satellite Image Processing Using Image Classification Algorithm for Flood Alerts
}

\author{
Seelam Ch Vijaya Bhaskar, ${ }^{1, *}$ Anitha $S^{2}$ \\ ${ }^{1}$ Department of Information Technology, MVSR Engg. College, Hyderabad, India. \\ ${ }^{2}$ Department of Electronics and Communication Engg. ACS College of Engineering, Bangalore, India \\ "Corresponding author. Email: seelam.chiranjeevi@gmail.com
}

\begin{abstract}
India is totally beaten by diverse range of artificial and natural disasters. It couldn't be controversial which contempt their natural and splendid beauty. By these devastations the country suffers through the government sets an interference and mitigation idea set in mitigation and interference plans, very little place into thought when the diversity occurs. This paper emphasis on the data engineering (ICT) associate degree appliance exceedingly in a very kind of a mechanical man based application that are mostly transportable that provides losses the aptitude for hunting facilitate once an incident or disaster strikes, additionally, individuals will advise other individuals of the danger ahead through the mobile application. Such that they will evade the world wherever the hazard is thru crowd sourcing. It uses user's movable intrinsical GPS and it shows the user various route to his destination such that he can avoid the disaster affected area and choose the different route.
\end{abstract}

Keywords: Disaster, Android, GPS, Mobile App, and ICT.

\section{INTRODUCTION}

In this chapter we will be discussing about the various disasters that is manmade and natural disasters. How they occur up to how much extent can they cause damage to the environment and also we will see a case study on a manmade disaster.

Disaster is a surprising, calamitous occasion bringing remarkable damage, loss, and destruction and devastation to existence and belongings. WHO defines catastrophe as "any prevalence that reasons harm, ecological disruption, loss of human existence, deterioration of health and fitness services, on a scale sufficient to warrant a top notch reaction from out of doors the affected community or vicinity". It is a natural coincidence, which causes extremely good damage to life, belongings and structures which cannot be reused. It may additionally be termed as "a functioning of society disruption in a severe manner, instigating considerable fabric, environmental or human victims that turn surpass the effected society potential to manage with the utilization of their corresponding sources. The damage because of disaster depends on Geographical area of place, weather of the location, kind of surface of Earth and degree of Vulnerability [15].

\subsection{Types of Disasters}

\subsubsection{Natural Disasters}

Natural disasters area unit large-scale geologic or meteoric or geologic measure having potential for causing property or life loss. This kind of disaster styles covers: Tropical Storms Floods Wildfires and Earthquakes Drought Severe storms and floods Tornadoes and severe storms hurricanes area unit were the foremost styles of natural disasters that are reported commonly in US. Sometime this type of metric events area unit headed by presidential "emergency declarations" necessitating native and state scheming beforehand the occasion, like protection and evacuations of community possessions. The disaster distress helpline offers area unit for taking those decisions or text during, before, and after the commencement of natural disaster $[6,7]$.

Natural disaster area unit large-scale geologic or meteoric occasions having the probable for purposing lifestyles or else belongings loss. These disasters varieties encompass: Tropical Storms Floods Wildfires and Earthquakes Drought Severe storms and floods Tornadoes and Severe Storms Hurricanes area unit were 
the foremost styles of natural disasters that are reported commonly in US. These meteoric activities location unit every now and then proceeded through constitutional "emergency declarations" requiring state and native designing earlier than the event, like protection and evacuations of community possessions. The disaster distress helpline region unit supplied to talk to those that decision or text earlier than, throughout, and once a herbal catastrophe.

\subsubsection{Artificial Disasters (Man/Human Made)}

Examples embrace accidents related to industrial, terrorist acts, mass violence incidents, and shootings act like natural adversities, these traumatic events forms will cause property and life loss. They will prompt evacuations additionally from indisputable zones and devastate social resources of health in the communities that were affected. In the consequence of tragic life loss which occurs on September 11, 2001 the security and sentiments loss and the well-being for the significant crucial ingredients on behalf of healthy and cheerful life that affects the voters of U.S in a dramatic manner. The employees of distress disaster helpline were being trained for replying all sorts of calls or the text messages that are associated with these kinds of disaster. The incidents of mass trauma infection, mass violence, community unrest incident, infectious disease outbreak, and the different traumatic events forms might bring out the emotions of folks in a sturdy manner. The occurrence of Ebola hemorrhagic fever moving many countries in geographic region, with restricted reported cases with in the US and alternative countries, might result in spirits of confusion and tension, for the purpose wherever it will inhibit with one's systematic monotonous. The reports of news and thus 24-hour cycle news might build even folks supplementary concerned once those type of actions happen $[8,9]$.

\subsection{Floods}

Typically, flood is the high-water level state together with the channel of river or on the coastal areas which leads to land inundation that was not submerged normally. The floods might be sudden (Flash floods) or gradual.

Floods are three types:

1) Flash floods-this kind occurs in six hours of rainfall that are heavy- and is typically related with cloud bursts, cyclones, and storms-immediate evacuation not possible all the times.

2) Riverine Floods

3) Urban Floods

\subsection{Causes of floods}

Causes may vary from urban to rural area

1) Heavy rainfall

2) Heavy river bed siltation

3) Blockage in the drains

4) Landslides

5) Construction of dams and reservoirs

6) Storm surges during cyclones Effects of floods
a. Loss of Life
b. Loss of property
c. Crop loss due to inundation
d. Change in soil characteristics

\section{LITERATURE SURVEY}

This statistic shows the number of Smartphone users in India from 2015 to 2022 . For 2017, the number of Smartphone users in India is estimated to reach 299.24 million, with the number of smartphone users worldwide forecast to exceed 2.3 billion users by that time.

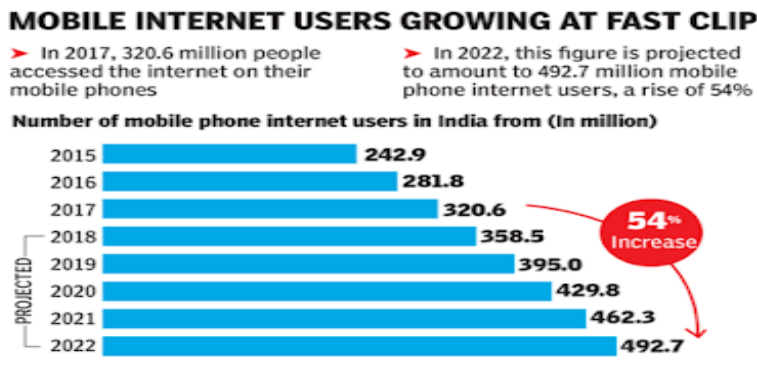

Figure 1 Number of smart phone users in India

This was presumably because of the cumulative smart phones affordability, significantly within the markets that are developing wherever native makers of Smartphone have created its approach noticeable within a market place. It has semiconductor diode for shoppers switch since their elementary feature receivers to possess the robust Smartphone's. Many applications that are utilized by users' area unit at its good phones area unit applications of Social media. Currently, it's now not employed as habits so as to stay connected to family, colleagues and friends. it's utilized currently in the crisis times. Data generation and activities dissemination Citizen-side area unit more and more taking part in a significant part in preparation of disaster, recovery and response warning. As a result of the general public area unit exploitation communal media throughout events that are emergency, most managers in emergency might begin to include their use additionally for their own activities.

A current member's survey of the International Association of Emergency Managers on the firstresponder.gov discerned about ninety fifth used different social networks or Facebook in their daily 
personal activities that concerns 0.5 employed this as an emergency forty third used twitter for collecting data from the over-all community and to express through the wide-ranging public emergencies throughout. This mobile device generation covers interaction of bit screen, camera, and Global Positioning Systems (GPS). Through their smart phones, they can offer citizens/users a report regarding incidents specifically for example the location of map, identification of causation definite location or else offering an of the incident indication (like informing by taking pictures). By means of technology availability the hunt flexibility and recognizing the disaster quickly not only poses the user constraints rather than the hunt facilitation flexibility which might be wont to specify various users who were in danger or else close to the disaster happenings. By means of intensive flooding on 2002, 2007, 2012, and 2013affects a huge variability of residents adversely and consequently the local economy, Djakarta, the Indonesia's Special Capital Region required to boost its response capability of disaster. They will indicate levels of stream and precipitation in three consequent stages: (1) notice, (2) warning, and (3) flood. The voters might embrace descriptive text and pictures, at which the unit area communicated with GPS knowledge and generated time stamp mechanically. The scheme in turn then designs reports entirely established from inhabitants on one town map. The voters in turn will recite this map in the app for ascertaining levels of stream in the interested areas and the current flood therefore circumstances about their own near areas and homes, as conferring by associated inhabitants.

\subsection{A Case Study on Hudhud Cyclone Which Occurred in Andhra Pradesh (2014):}

a. Enormously Cyclonic Storm Hudhud Severely has the robust cyclone in tropical which in turn causes wide range of damage and extreme loss of life.

b. Hudhud instigated wide-ranging impairment to the Visakhapatnam city and the Vizianagaram and Srikakulam neighboring districts of Andhra Pradesh.

\section{i. $\quad$ History}

1. The term Hudhud originated from Oman.

2. The HudHud denotes to rabic \& Hoopoe Bird in

3. The Hudhud instigated from a system of lowerpressure which was made by the influence of higher air circulation cyclone in the sea of Andaman.

\section{ii. Intensity}

1. Almost $70 \%$ of trees were being uprooted.

2. The speed of wind is around $170-180 \mathrm{~km} / \mathrm{hr}$.
3. In Vishakhapatnam $70 \%$ of power lines were being damaged.

4. Around $2250 \mathrm{~km}$ roads length was dented in the nation.

5. Three districts viz. Srikakulam, Visakhapatnam, Vizianagaram among 356villages in the 59 Mandal's were affected greatly by cyclones.

iii. Effect of Hudhud

1. The Hudhud instigate wide spread impairment to the Visakhapatnam city and the districts of Vizianagaram and Srikakulam that are neighbouring in Andhra Pradesh.

2. Hudhud instigated as a minimum of 124 deaths in Nepal and Andhra Pradesh.

3. The costs of total damage were being assessed to be 21908 crores at least in the AP state

4. A huge quantity of property loss occurs for both humans and governments

5. Thus, this in turn makes Hudhud the utmost cyclone that are destructive and should ever hit India and the subsequent most destructive cyclone was recorded in Nargis by 2008 [10-12].

\section{DESIGN OF ANDROID BASE FLOOD ALERT SYSTEM}

\subsection{Purpose of the system}

India is assaulted totally by diverse disasters naturally and artificially. It can't be controversial which contempt their natural and splendid beauty, the country in turn suffers by these kinds of devastations. Though the govt. must establish extenuation and interference plans, very tiny residence into thought once the disaster occurs. The paper focuses on the appliance of data engineering (ICT) associate degree exceedingly in a very kind of a mechanical man based mostly application of mobile that provides victims the aptitude to hunt facilitate once an incident or disaster strikes. Additionally, individuals will advise other individuals of the danger ahead through the mobile application. So they will evade the world wherever the danger is thru crowd sourcing. It uses user's movable intrinsical GPS and it shows the user various route to his destination such that he can avoid the disaster affected area and choose the different route [13-15]. 


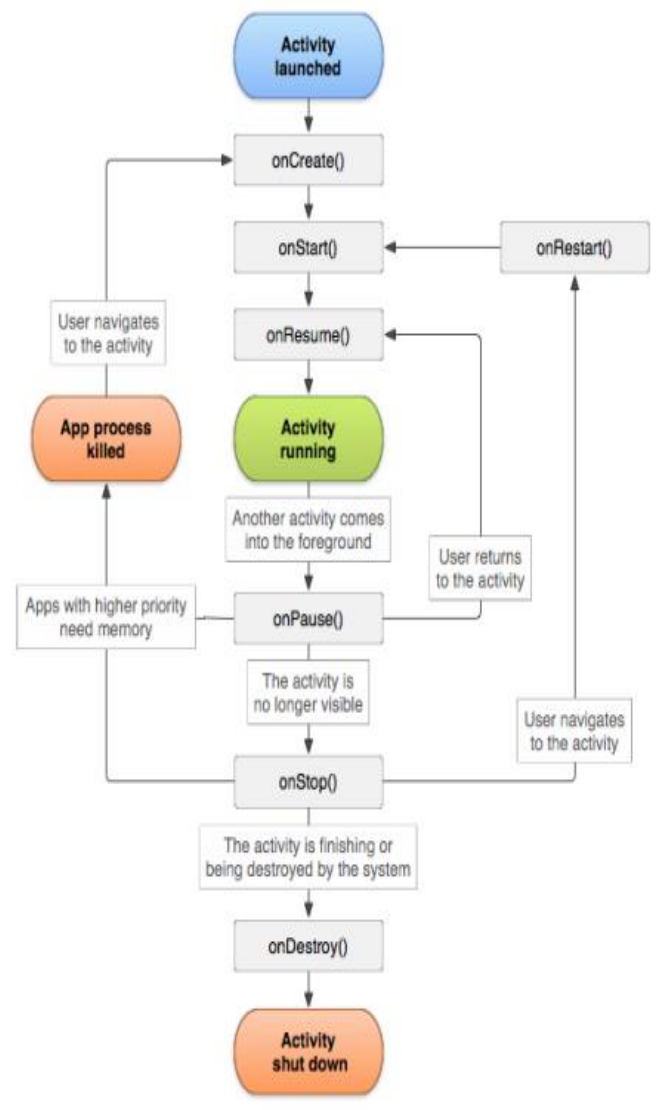

Figure 2 A simplified illustration of the activity life cycle.

\subsection{Proposed system}

Our aim is to build a system which lets the user to share the information of a particular place where some disaster occurred by sharing his location using the mobile phone build-in GPS system. So, we created a chat box where different users can communicate and if some disaster or some problem occur place they can share the information in the chat box and all the other users can avoid visiting that place for some time. If a user is travelling to a destination and if the affected place is in his route it also allows the user to choose the different route which is safe [16-18].

\section{Advantages:}

1. Monitor the places that matter to you.

2. Track hazards on the map.

3. Easy to view alert feed with the ability to remove alerts once you read them.

4. Help friends and families in areas where flood and flash flood occurred

\section{DESIGN OF MODULES}

This section discusses about the modules which were developed on the android studio while developing the application a detailed description of each module is given below.

\subsection{Modules of the System}
1. Register
2. Login
3. Chat room
4. Main Activity
5. User List Fragment
6. Location Service

\subsubsection{Registration}

A registration kind may be a list of fields that a user can input file into and worker under an organization or individual. There square measure several reasons why you'd desire a person so as to fill the kind of registration. The companies in turn employ the registration forms for checking the services, subscriptions, or the alternative plans or programs. The page of registration ought to get on your landing page and will not be listed on another web site, for the simplest results. This way, your client or shopper won't be tempted to go away your website before sign language up. You ought to totally check all fields on your registration kind to create positive that they work properly and square measure formatted professionally

\subsubsection{Login Module}

The login should be a credentials set that won't verify the user. Almost, these contain a password and user name. Though, the login might embody various info, like a passcode, passphrase, or PIN number. Approximately few logins need a symbol of biometric, like a membrane scan or finger print. The login area unit utilized through PC applications, mobile apps, and websites. They're a live security intended to forestall illegal admittance to information that are confidential. Once there is a failure in login (i.e., the password and user name combination didn't verify a user account), then the user was disallowed entry. Most systems need distinctive usernames that ensures each login of user's is different completely. By the advanced additional level, the login offers a layer of security among secured and unsecured action.

\subsubsection{Chat room}

The main usage of a chat room is to transfer info through typescript having a group of users alternatively. Usually speaking, to converse the flexibility with several people in the similar communication speech distinguishes rooms of chat from prompt programs of electronic messaging, which were usually designed additionally aimed at corresponding message that permits users to speak with one another through instant 
electronic messaging. Text is displayed instantly within the speech communication of chat room's log once handler successes send or enter. Alternative users enclosed within the chat session are ready to see what another user variety. America on-line created chat rooms well-liked within the Nineteen Nineties once they created subject-specific ones. Chat rooms also are used by companies to permit their workers to speak from several locations. Users communicate with one another through the net, historically in plain text solely. newer developments in net technology currently permit the transmission of pictures and emoticons in an exceedingly chat space likewise.

\subsubsection{Main Activity}

The Activity category may be a crucial element of associate degree robot app, and therefore the means activities area unit launched and place along may be a elementary a portion of application model platform's. in contrast to paradigms programming at which the apps area unit launched with a main methodology, the robot system initiates code in associate degree the instance activity through invoking exact strategies of recall which resemble to explicit lifecycle stages.

\subsubsection{User list Fragment}

It is also possible to consider a fraction to be a standard section activity of associate degree, having their individual lifecycle and in turn attains their respective events of inputs and will be capable of adding or taking away the activities that are running (sort of sort of a "sub activity" that you just can employ in several activities). This lesson shows away to extend the Fragment category victimization the Support Library therefore your app is compatible by running system devices versions as small as Android1.6.

\subsubsection{Location services}

In case the app demand location or obtain updates on permission, this device should be changed to acceptable settings such as Wi-Fi scanning or GPS. Instead of sanctioning services directly like GPS of device, corresponding application in turn stipulates the level of desired power/accuracy consumption and desired update interval, and also the device mechanically makes the acceptable changes to system settings. These square measure settings drew through the condition Request knowledge object. This message displays the way for using shopper Settings to inspect that square settings enabled measure and knack the Settings dialog situation for the handler to appraise their locations with one faucet. For using the situation services provided by Google Play Services and also the united location supplier, your app exploitation is connected to the Settings shopper, then check the present location settings and in turn hasty the handler to alter the anticipated settings if mandatory [19-23].

\section{RESULTS}

This screen shot shows user registration where user has to provide his details which are asked in the registration page and he has to submit the details. The details include users Email and password the user has to type the password twice to confirm if he enters the wrong password during confirmation then a popup will be shown that he is entering the wrong password. Once the details are submitted this will be sent to database which is the database being used in the design the details of the user are stored and the user is directed to the next page

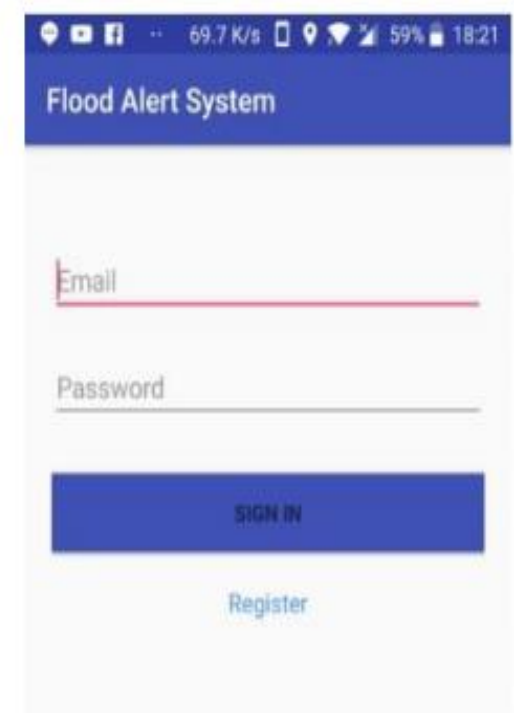

Figure 3 User Login

This is the user login page where the user can login through the details provided by the user during registration phase. The user has to provide the same email and Password if the user wish to login to the app. If he enters anything wrong a popup will be shown where he is making the mistake. 


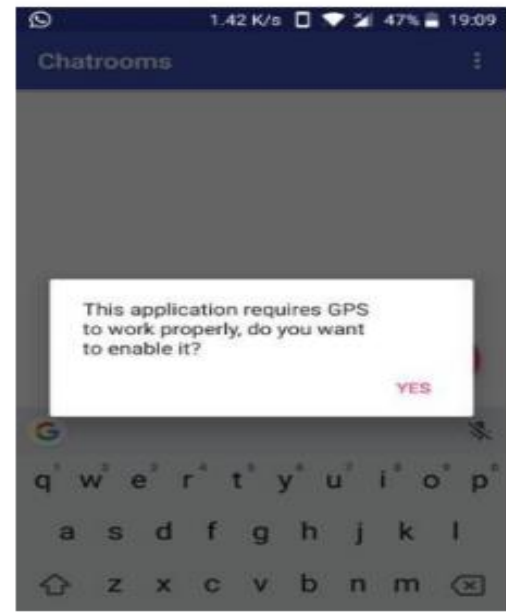

Figure 4 Granting Location Permission

Once the user log's in providing the details the user has to give his mobiles location access to the app. The Location permission is asked because we want to store the location coordinates of the user on the map. If user gives the permissions to the app the app works else, it won't. This location coordinates are used to show the user on the map if the user provides any information on the map then we can see the coordinates where he is located and can get alerted
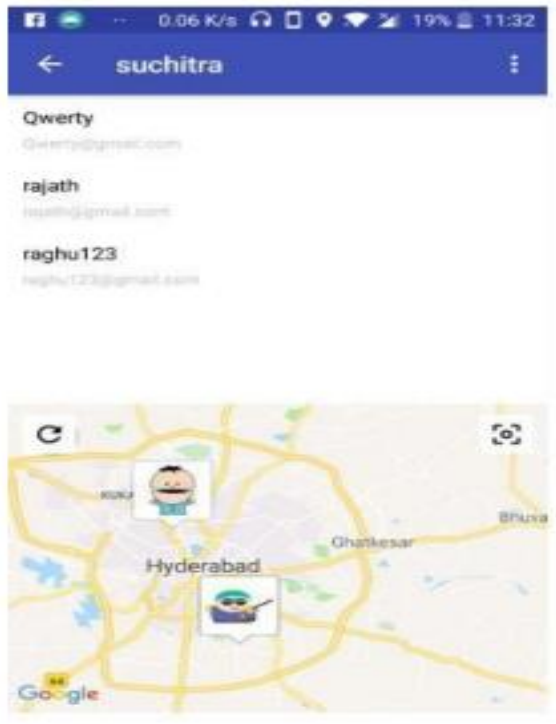

\section{Figure 5 User List}

When user clicks the top right dots, he can see the user list along with their location on the map. User can expand the maps if he wants and can route to any area he wishes. How this map is going to help people? When someone gets an information's that the area is flooded or affected with another kind of disaster then maps shows not only one route we use polylines to provide various routes to the user such that he can avoid the route on which the affected area falls and can choose another route to reach his destination safely as shown in the below figure. The user can then move to Google maps through our app and can get the dynamic data about their route.

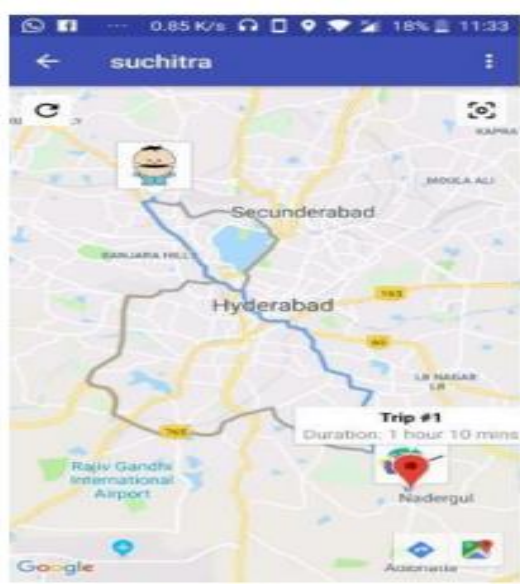

Figure 6 Various routes to a place

When user select a point on the map then routes between those two locations will be displayed on the map, then user can choose their preferred routes. In Bottom right corner there are two icons they're used to show direction directly on Google maps and provide navigation.

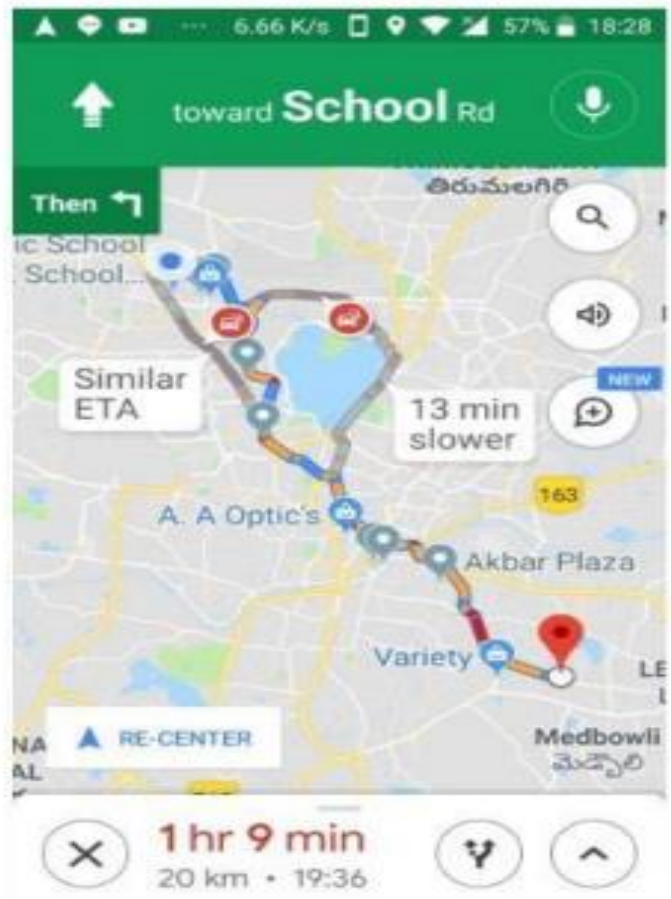

Figure 7 Routing using Google Map

Here navigation is shown according to the user preferred routes previously on the App, User can navigate accordingly to his choice as location is fixed previously on the application 


\section{CONCLUSION}

Although the government has set in mitigation plans, it provides alert that will help the people to avoid the flooded regions. An application by which the user can send the information/alerts about a location to the people so that the people who are planning to go that location can avoid visiting it for some time. Once the location coordinates are shared the users can view it on the map using the link and our app will help them to reroute. And help them to reach their destination by using the other route.

\section{AUTHORS' CONTRIBUTIONS}

Aim to develop a model for societal application in the area of Disaster Monitoring of Satellite Image Processing using Image Classification Algorithm for Flood Alerts to guide the public move from effected are to safe location.

\section{ACKNOWLEDGMENTS}

I like to thank my research supervisor Dr. Anitha S, Professor ACS College of Engineering, Bangalore for continuous guidance in construction of paper and also extend my sincere gratitude to my parents and my family members for continuous encouragement and support.

\section{REFERENCES}

[1] Pratibha S., Jayashree S., Sarika S., Solai A. L., A Novel Approach for Early Flood Warning using Android and IoT Second International Conference on Computing and Communications Technologies, IEEE, 2017.

[2] Balaji. V., Akshaya A., Jayashree N., Karthika T, Design of ZigBee based Wireless Sensor Network for Early Flood Monitoring and Warning System IEEE International conference on technological innovations in ICT for Agriculture and Rural Development, 2017.

[3] Indira Priyadarshini, Kabita Sahoo, Chandrakant Mallick, Flood Prediction and Prevention through Wireless Sensor Networking (WSN): A Survey, International Journal of computer applications, vol. 113, Issue 9, 2015.

[4] Diogo de Souza Junior, Iago Freitas Cardoso, Marcos Rodrigo Momo, Brazil, Tool-based Mobile Application Applied to the Monitoring System and Flood Alert, Ninth International Conference on Complex,Intelligent, and Software Intensive Systems, 2015

[5] M. Geetha, K. Raja Shekhar, V. Dhana Raj, A. Pravin, IoT based Flood Monitoring System Using LPC2148, International journal of innovative technologies, Vol. 5, Issue 5, pp. 0916-0920, May 2017.

[6] Jagadeesh Babu Mallisetty, Chandrasekhar V, Internet of Things BasedReal-Time Flood Monitoring and Alert Management System, International Journal of pure and applied mathematics, vol. 118, Issue 17, 2018.

[7] Syed Nazmus Sakib, M. Tanjea Ane, Nafisa Matin, Shamim Kaiser, An Intelligent Flood Monitoring System for Bangladesh Using Wireless Sensor Network,5th International conference on informatics, electronics, and vision, IEEE, May 2016.

[8] Jyh Horng Wu, Chien Hao Tseng, Lun Chi Chen, Shi-Wei Lo, Fang- Pang Lin, Automated Image Identification Method for Flood Disaster Monitoring in Riverine Environments: a case study in Taiwan, International conference on industrial electronics and applications, Jan 2015.

[9] Victor Seal, Arnab Raha, Shovan Maity, Souvik Kr Mitra, Amitava Mukherjee, and Mrinal Kranti Naskar, A Simple Flood Forecasting Scheme using Wireless Sensor Networks, International Journal of ad hoc, sensor \& ubiquitous computing, vol. 3, Issue 1, Feb 2012.

[10] K. Yu, L. Tan, L. Lin, X. Cheng, Z. Yi and T. Sato, "Deep-Learning-Empowered Breast Cancer Auxiliary Diagnosis for 5GB Remote E-Health," IEEE Wireless Communications, vol. 28, no. 3, pp. 54-61, June 2021, doi: 10.1109/MWC.001.2000374.

[11] K. Yu, L. Tan, S. Mumtaz, S. Al-Rubaye, A. AlDulaimi, A. K. Bashir, F. A. Khan, "Securing Critical Infrastructures: Deep Learning-based Threat Detection in the IIoT", IEEE Communications Magazine, 2021.

[12]L. Tan, K. Yu, A. K. Bashir, X. Cheng, F. Ming, L. Zhao, X. Zhou, "Towards Real-time and Efficient Cardiovascular Monitoring for COVID-19 Patients by 5G-Enabled Wearable Medical Devices: A Deep Learning Approach", Neural Computing and Applications, 2021, https://doi.org/10.1007/s00521021-06219-9

[13]Z. Guo, A. K. Bashir, K. Yu, J. C. Lin, Y. Shen, "Graph Embedding-based Intelligent Industrial Decision for Complex Sewage Treatment Processes", International Journal of Intelligent Systems, 2021, doi: 10.1002/int.22540.

[14]Z. Guo, K. Yu, Y. Li, G. Srivastava, and J. C. -W. Lin, "Deep Learning-Embedded Social Internet of Things for Ambiguity-Aware Social Recommendations", IEEE Transactions on Network Science and Engineering, doi: 10.1109/TNSE.2021.3049262.

[15] K. Yu, M. Arifuzzaman, Z. Wen, D. Zhang and T. Sato, "A Key Management Scheme for Secure Communications of Information Centric Advanced 
Metering Infrastructure in Smart Grid," IEEE Transactions on Instrumentation and Measurement, vol. 64, no. 8, pp. 2072-2085, August 2015.

[16] Puttamadappa, C., and B. D. Parameshachari. "Demand side management of small scale loads in a smart grid using glow-worm swarm optimization technique." Microprocessors and Microsystems 71 (2019): 102886.

[17] Subramani, Prabu, Ganesh Babu Rajendran, Jewel Sengupta, Rocío Pérez de Prado, and Parameshachari Bidare Divakarachari. "A block bidiagonalization-based pre-coding for indoor multiple-input-multiple-output-visible light communication system." Energies 13, no. 13 (2020): 3466.

[18] Rajendrakumar, Shiny, and V. K. Parvati. "Automation of irrigation system through embedded computing technology." In Proceedings of the 3rd International Conference on Cryptography, Security and Privacy, pp. 289-293. 2019.

[19] Hu, Liwen, Ngoc-Tu Nguyen, Wenjin Tao, Ming C. Leu, Xiaoqing Frank Liu, Md Rakib Shahriar, and SM Nahian Al Sunny. "Modeling of cloud-based digital twins for smart manufacturing with MT connect." Procedia manufacturing 26 (2018): 11931203.

[20] Seyhan, Kübra, Tu N. Nguyen, Sedat Akleylek, Korhan Cengiz, and SK Hafizul Islam. "Bi-GISIS KE: Modified key exchange protocol with reusable keys for IoT security." Journal of Information Security and Applications 58 (2021): 102788.

[21] Nguyen, Tu N., Bing-Hong Liu, Nam P. Nguyen, and Jung-Te Chou. "Cyber security of smart grid: attacks and defenses." In ICC 2020-2020 IEEE International Conference on Communications (ICC), pp. 1-6. IEEE, 2020.

[22] Arun, M., E. Baraneetharan, A. Kanchana, and S. Prabu. "Detection and monitoring of the asymptotic COVID-19 patients using IoT devices and sensors." International Journal of Pervasive Computing and Communications (2020).

[23] Kumar, M. Keerthi, B. D. Parameshachari, S. Prabu, and Silvia liberata Ullo. "Comparative Analysis to Identify Efficient Technique for Interfacing BCI System." In IOP Conference Series: Materials Science and Engineering, vol. 925, no. 1, p. 012062. IOP Publishing, 2020. 